maintaining them. To the uninitiated the situation is bewildering. CloudsleyThompson has examined a considerable literature as well as conducting numerous significant investigations of his own. He reviews the variety of our knowledge as it stands at present and discusses the relevant physical principles.

Different reptiles can operate over much wider ranges of bodily temperatures than can mammals or birds; nonetheless they generally have fairly well defined preferred temperatures. We learn, for example, that some select the temperature of their surroundings, that some lizards can regulate heat gain and heat loss using the sun as the source of energy, that some large snakes can so reduce their exposed surface area by coiling that the generation of metabolic heat becomes significant. Some, particularly desert forms, operate a rigorous water-saving economy; freshwater forms are understandly lax in this respect.

The author has had the happy idea of supplementing the list of literature citations with a list of further references - this should be a considerable help to others considering entering the field. Fragments of a pattern begin to emerge but it is too early to hope for a new set of broad generalisations. Cloudsley-Thompson has taken a first and essential step in this direction and placed us in his debt in so doing.

GARTH UNDERWOOD

\title{
The Book of Reptiles, by R.A. Lanworn. Hamlyn, £1.95.
}

This is an attractive addition to the fast increasing library of modern reptile books. Almost everyone, it seems, wants to know about reptiles-except perhaps the academic zoological establishment, whose courses seldom do much to encourage the university student with herpetological interests.

$\mathrm{Mr}$ Lanworn was in charge of the Reptile House in the London Zoological Society's Gardens for many years, and some readers, the reviewer among them, will have received their first introduction to living reptiles from his capable hands; they will remember his kind and thoughtful advice on the manifold problems of keeping reptiles in captivity and his wide knowledge of these animals, which is here deployed to good effect.

He gives an excellent popular account of the main adaptations exhibited among the 6000 or so species of living reptiles, touches on the long-past Golden Age when dinosaurs were the dominant forms of terrestrial life, explains the sad fate of all too many reptiles kept as pets in this country, which languish and soon die because of their owners' lack of knowledge of their basic needs and habits. He also describes the ruthless exploitation which many types such as crocodilians and turtles have suffered at the hands of man in his search for attractive leathers and table delicacies, and the less obvious but perhaps even more serious danger from habitat destruction. A final chapter deals with the task of conservation, and mentions the role of such bodies as IUCN and the Charles Darwin Foundation which is doing so much to ensure the survival of the giant tortoises and unique iguanas of the Galapagos Islands.

This finely illustrated book is recommended very strongly to those who require a reliable and readable introduction to the reptiles, as they live in the rapidly changing man-dominated environment of the modern world.

A.d'A. BELLAIRS

\section{Wildfowl in Captivity, by Richard Mark Martin. John} Gifford, $\mathrm{f} 1.75$.

Written by a real enthusiast who knows his subject, the book fulfills a great need, for the amount of up-to-date practical duck-keeping literature is very 
small indeed. His advice on general management is sound, and anyone thinking of starting a waterfowl collection would do well to read and digest its contents throroughly. Many people want to have a few ornamental ducks on their garden pond, and so many start without any idea of the problems likely to be encountered. Richard Martin has gone a long way to pointing out the many pitfalls. I particularly like the way the wildfowl have been divided into tribes to make it easier for the beginner to understand. The appendix contains much useful information all of which is extremely practical; it should always be readily available for reference, particularly during the breeding season. The excellent colour photographs add to the beauty of this book. As a wildfowl breeder of some years standing, I would thoroughly recommend it, not only to those just about to start on this fascinating hobby but also to those experts who can always improve their knowledge from the experience of others.

CHRISTOPHER MARLER

The 14 national parks in Yugoslavia (one of which is not accepted in the UN List) are well on the way to protecting all types of landscape in the country, according to $T$. Wojterski in a paper on the parks published by the Polish journal Ochrana Przyrody Annual No. 36 (Krakow, 1971), with a substantial English summary. Each park is described with a map, but the summary makes no mention of any wildlife. Because the parks have to be self-supporting, they suffer from timber cutting and grazing and also from what the author refers to as the 'violent development' of mass tourism.

Skaftafell: Thingvellir by Birgir Kjaran (Bokantgafan orn og orlygur H. F., Reykjavik, $\mathbf{x x}$ ) is a short general account, in four languages (Icelandic, Danish, English and German) of Iceland's two national parks, the first established in 1967 with the aid of the World Wildlife Fund, the second believed to be the assembly site of Europe's first parliament. The colour photographs of the dramatic landscapes are outstandingly good.

A useful, well produced and illustrated paperback Guide to Malawi's National Parks and Game Reserves by G. D. Hayes (Government Printer, Zomba, $£ 1$ ) includes, as well as an account of the reserves, their history etc., 70 pages of descriptions of the mammals, with good drawings, and of their tracks, also illustrated.

\section{Brief Reviews}

In the third edition of Environmental Conservation (John Wiley, Chichester, $£ 4.50$, paperback £3), Raymond F. Dasmann, now Senior Ecologist at the IUCN has added new material at the end to update it and also broaden its scope, which in the original is primarily concerned with North America, but the basic survey remains valid and the urgency for getting it across even greater. In a new preface he writes that if he were to sum up the environmental situation in the $1970 \mathrm{~s}$ in one sentence it would be, 'The problems of the human environment are far worse than any of us fully understands.' He adds, 'There are few grounds for optimism but there is cause for hope if public awareness can be translated into effective action.'

The new edition of $A$ Guide to Mexican Mammals and Reptiles by $\mathrm{N}$. Pelham Wright, an Englishman who lives in Mexico, is a neat pocket $\left(6 \frac{1}{2} \times 4 \frac{1}{2}\right.$ ins) paperback, with perfect illustrations, some in colour, published by Mexico City Museums at US \$2.00. 